\title{
ADOPT DIET
}

On drink On fieldwork Or

Fragile, Tenuous, Desperate, Uncertain, Contingent, Volatile, Fun.

I Am as It Is.

(or seems)

And, ever:

It might just as well have been otherwise.

Adopt diet

(gesture of necessity)

Adapt appetite

(gesture of guest/guess)

self-led by friends

those who are not you

yourself

Either/Both/And

Yes. Yes yes.

Drink deep!

Have heard more today than

in the last

combined.

Guard down,

from state of guard always down.

Open. Open:

soon enough requires no effort.

At all.

Or won't. 


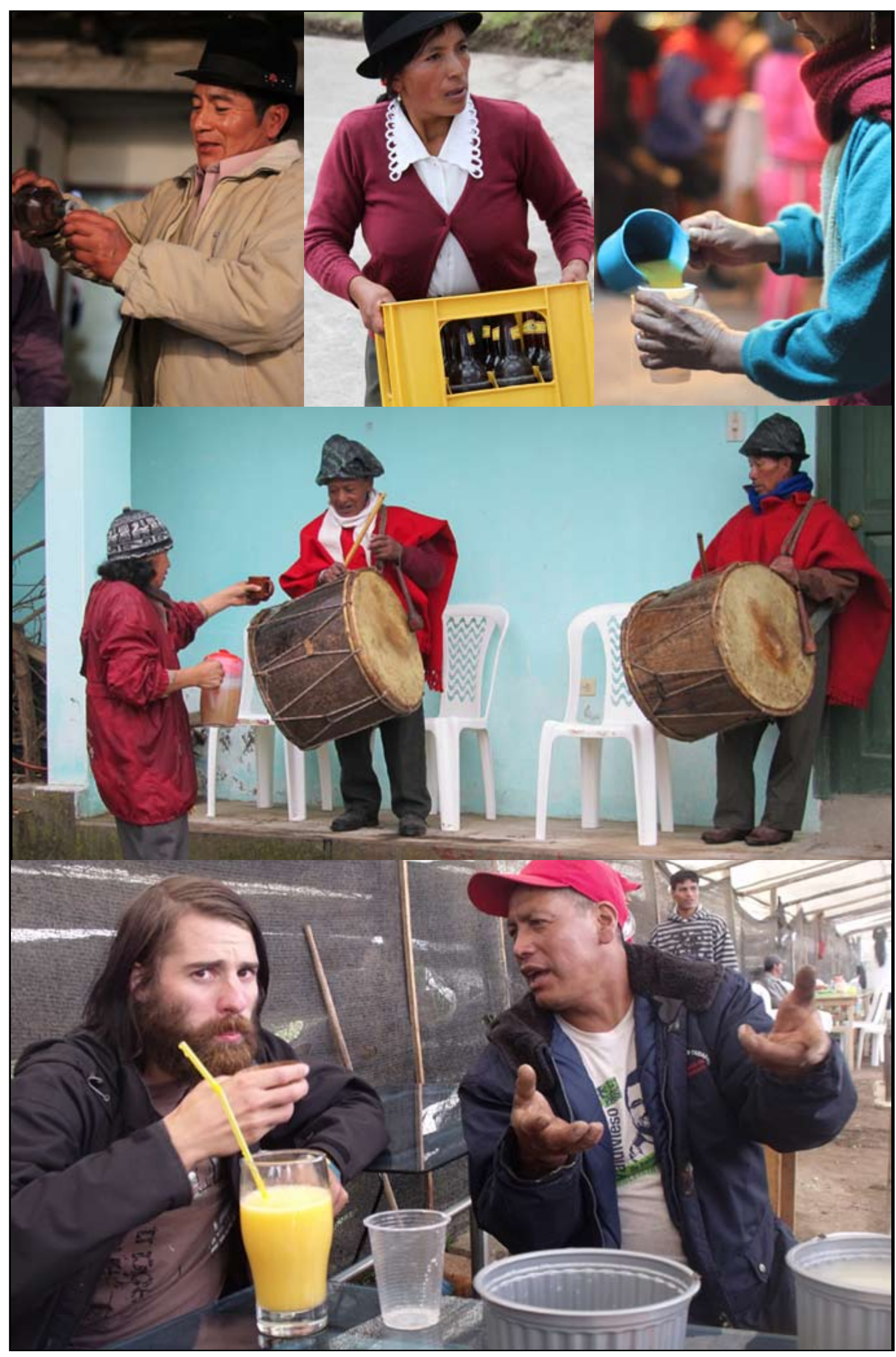

